\title{
Understanding and Reducing Landslide Disaster Risk: Challenges and Opportunities for Italian Civil Protection
}

\author{
Pagliara Paola, Onori Roberta, and Ambra Sorrenti
}

\begin{abstract}
This work provides an overview of the hydraulic and hydrogeological warning system, starting with a description of the tasks carried out by the Italian Civil Protection Department and in an Italian context. The Italian early warning system was put in place with the intent of following a specific approach, also confirmed by the Sendai Framework, that has shifted its focus towards Disaster Risk Management (DRM) as opposed to Disaster Management. The aim of the paper is to stress the challenge and the relevance of the approach to reducing landslide risk, which requires the involvement of many actors, including scientists and decision makers, as well as international, national, local, governmental, and non-governmental institutions, to find, develop and share new and best practices in the technical-scientific and regulation fields in order to make the necessary tools and instruments available to carry out the challenging tasks defined in the Sendai Framework toward real Disaster Risk Reduction.
\end{abstract}

\section{Keywords}

Early warning system • Disaster risk reduction - Landslide

\section{Italian Civil Protection Department}

\section{Outline and Mission}

The Italian national territory is exposed to a broad range of natural hazards, including landslides, that every year cause a significant number of casualties and considerable economic

P. Paola $(\bowtie)$

Manager of the National Centre for Forecasting and Surveillance for Hydrologic and Hydraulic Risk, Italian Civil Protection Department (DPC), Rome, Italy

e-mail: paola.pagliara@protezionecivile.it

O. Roberta

Italian Civil Protection Department (DPC), National Centre for Forecasting and Surveillance for Hydrologic and Hydraulic Risk, Rome, Italy

e-mail: roberta.onori@protezionecivile.it

A. Sorrenti

International Relation Unit, Italian Civil Protection Department (DPC), Rome, Italy

e-mail: ambra.sorrenti@protezionecivile.it

(C) The Author(s) 2017

K. Sassa et al. (eds.), Advancing Culture of Living with Landslides, DOI 10.1007/978-3-319-59469-9_16 damage. In some cases, the vulnerability of the population and the environment is increased by human activities.

In this perspective, within the National Civil Protection Service (Law n. 225/92 and all the amendments and modifications of Law n. 100/12), the Italian Civil Protection Department (DPC) is responsible for a wide array of sectors pertaining to civil protection, ranging from prevention, forecast and assessment, early warning and alert systems to emergency response and recovery from emergency.

The DPC is a structure of the Presidency of the Council of Ministers. It is responsible for coordinating the National Civil Protection Service, which includes local authorities, research institutions, private companies, volunteer associations and all Italian operational forces. During major emergencies, it ensures horizontal (line Ministries) and vertical (central-local) coordination. It plays a leading role, in cooperation with regional and local governments, to ensure risk prevention, forecasting and monitoring activities, as well as emergency preparedness and intervention procedures in case of on-going or upcoming disaster events. 
For this purpose, it relies on a well-developed network of risk monitoring and forecasting centres (one in each region, besides the central one located in the DPC Headquarter premises, which has a coordinating role). They work closely with the local branches of the National Civil Protection Service and the scientific community, as well as from a national inter-institutional operational room, where all the operational forces are present 24/7.

DPC promotes drills, national and international training projects and activities that contribute to spreading the culture of civil protection based on prevention and preparedness rather than just response.

In the framework of its guiding role in the phase of emergency preparedness, the DPC:

- develops and implements contingency plans for major events, as well as awareness-raising campaigns, jointly with local governments and volunteer associations throughout the country;

- provides technical support to local government for the elaboration/updating of contingency plans, including testing activities (such as simulations and field exercises);

- issues guidelines, standard operating procedures aimed at regions, provinces and municipalities, to prepare and implement prediction and prevention programs based on risk scenarios;

- promotes field exercises for testing multi-level co-ordination (international, national and local), including host nation support aspects.

The DPC operates at an international level aimed at advancing work on disaster risk management and disaster risk reduction by promoting and exchanging knowledge and experience in these domains.

In particular, the DPC is involved in a consistent number of initiatives of international cooperation and capacity-building related to different types of risk in the framework of programs and projects, mainly financed by the European Union, involving the EU countries, the Balkans, North Africa and Middle Eastern countries.

Due to its role in coordinating the National Civil Protection Service, the DPC is the focal point of the Union Civil Protection Mechanism since its establishment in 2001. The Mechanism, revised in 2013, aims to strengthen cooperation between the Union and the Member States and to facilitate coordination in the field of civil protection in order to improve the effectiveness of systems in prevention, preparedness and response to natural and man-made disasters. In this regard the DPC has been strongly engaged in contributing to advance the work on these three pillars, both from policy and operational points of view.
Furthermore, in cooperation with components of the Civil Protection System, the Department is committed to the design, establishment and testing of national and multi-national resources and capacities to be offered and deployed upon request from a country hit by a disaster through the Mechanism.

Among the valuable achievements in the scientific field, it is worthwhile to mention that the DPC has actively contributed, through its ten-year participation in the GMES projects that led to the current operational service, to the implementation of the newly established Copernicus Emergency Mapping Service (EMS).

Relations between the DPC and the international organisations are very fruitful as well. Through Inter-governmental processes and initiatives, the DPC contributes in advance to DRR and DRM topics at international level as well as at regional and national ones.

In this regard the collaboration with the United Nation Office for Disaster Risk Reduction UNISDR has been constant over the years, offering opportunities to foster disaster risk reduction policy, strategies and plans.

After the adoption of the Hyogo Framework for Action, Italy established the National Platform for Disaster Risk Reduction under the coordination of the DPC. The Italian commitment in DRR has been further renewed with the Sendai Framework for Disaster Risk Reduction 2015-2030.

The Department participates actively in several initiatives promoted by UNISDR in different domains, such as 'Making cities resilient', 'Indicators and Terminology related to DRR', 'School Safety and Science' and technology.

\section{The Italian Hydraulic and Hydrogeological Early Warning System}

\section{Role and Responsibilities}

In Italy, the separation of responsibilities is clearly stated in the text of Law 225/1992, and further specified in the Decree-Law of 15 May 2012, n. 59, converted with amendments by Law 12 July 2012, n.100.

In particular, regarding the "prevention" of hydraulic and hydrogeological risk, there are two major categories (http:// www.protezionecivile.gov.it/):

- Structural prevention is based on the implementation of structural interventions aimed at mitigating the risk conditions through the reduction of danger and the probability of occurrence of a hydrological or hydraulic phenomena in a given time interval. In this context, measures include works of soil conservation measures 
such as the consolidation of the slopes, embankments, dams, spillways, etc. Planning, programming and implementation of these works is not, however, due to the expertise of the National System of Civil Protection, but to other institutions such as the Ministry of Environment, Regions and Basin Authority and the local authorities, on the basis of provisions mostly established at regional level.

- Non-structural prevention refers to actions and measures in the first place to mitigate risk by the reduction of exposure. The early warning system for hydraulic and hydrogeological risk, the regional offices, the emergency plans, the provision of information to the population, etc. are all examples of non-structural prevention The main purpose of these interventions, which refer to the competence of the different components of the national civil protection system, essentially consists in ensuring the safety and protection of human lives. In addition, territorial and urban planning, which are important for a complete and efficient soil protection policy, fall exclusively within the institutional powers of local governments. Since then, the crosscutting nature of soil defence and the fragmentation of responsibilities have clearly stressed the need for closer integration between the different institutions, for various reasons, demanding a wider level of competence, including forecasting, prevention and mitigation of geological risk.

\section{National Centre for Forecasting and Surveillance for Hydraulic and Hydrogeological Risk}

To address its mandate, the Civil Protection Service has organized a comprehensive system that includes a great number of both local and centralized resources (Boni et al. 2015). In particular, for hydraulic and hydro-geological risk, a national alert system is run by the DPC and regional authorities built around a network of Functional Centres (Boni et al. 2015) providing service in two phases - forecast of expected flooding and landslides and then monitoring and observation of current weather, flooding and geological conditions. This system, defined by the Directive of the President of the Council of Ministers 27 February 2004, was the result of a long sequence of disasters.

For these purposes and for the decision-making and the consequent assumption of responsibility, the Functional Centre is organized as a network consisting of 21 regional or decentralized Centres, based in the Regions or Autonomous Provinces, and by a Central Functional Centre, based at the Department of the National Civil Protection (Fig. 1).
Each Functional Centre is in charge of carrying out forecasting, real-time monitoring and surveillance of meteorological phenomena, with the consequent evaluation of the expected effects on people and things in a certain territory (alert zone).

The forecast phase consists in the evaluation, supported by appropriate numerical modelling, of weather, snow, hydrogeological and geomorphological conditions and the corresponding potential impact that these conditions may have on the integrity of life, property, settlements and environment. The phase of monitoring and surveillance is articulated in the qualitative and quantitative observation, direct and instrumental, of the meteorological and hydrogeological event in progress and in a short prediction of its effects by the measures collected in real time.

Rainfall thresholds are used to measure the expected risk scenario of geological and flood events in the alert zone. The thresholds identify the precipitation critical values and the effects expected if the events overcome the thresholds described in hydrogeological or hydraulic type event scenarios, in relation to the different levels of criticality defined (ordinary criticality, moderate, high).

Like the establishment of the alert areas, rainfall thresholds also were defined by the Regions and Autonomous Provinces of Understanding with the Department of National Civil Protection.

The use of thresholds is however not the only factor to be taken into account. The previous precipitation determines the degree of humidity of the soil and can affect the assessment of the expected risk scenario. The water levels of the main rivers have to be also considered, as well as sudden increases of temperature that can cause melting of the snowpack, factors such as landslides that are already active, and the geomorphological characteristics of the specific area.

On the basis of the criticality level, evaluated by the Functional Centre, the regional civil protection in charge may define corresponding alert levels, using three colour codes: yellow, orange and red, identifying from the lower to the maximum alert level. Each Municipality, taking into account the alert level, has to activate the corresponding operational phase (attention, pre alarm and alarm), as defined in each emergency plan. The alert system reaches its goal when the citizen is aware of self-protection rules and what to do in relation to the event that is taking place (Fig. 2).

In order to make this system effective, specific information campaigns for the general public take place both yearly ("I don't take risks" campaign, carried out in more than one hundred municipalities with the support of local volunteers, ad hoc trained) (http://iononrischio.protezionecivile.it) and when an event occurs, after which the population needs to be informed on what happened, what they can do and what they can expect to happen in the near future. 
Fig. 1 Network of Italian functional centre for forecasting and surveillance for hydraulic and hydrogeological risk

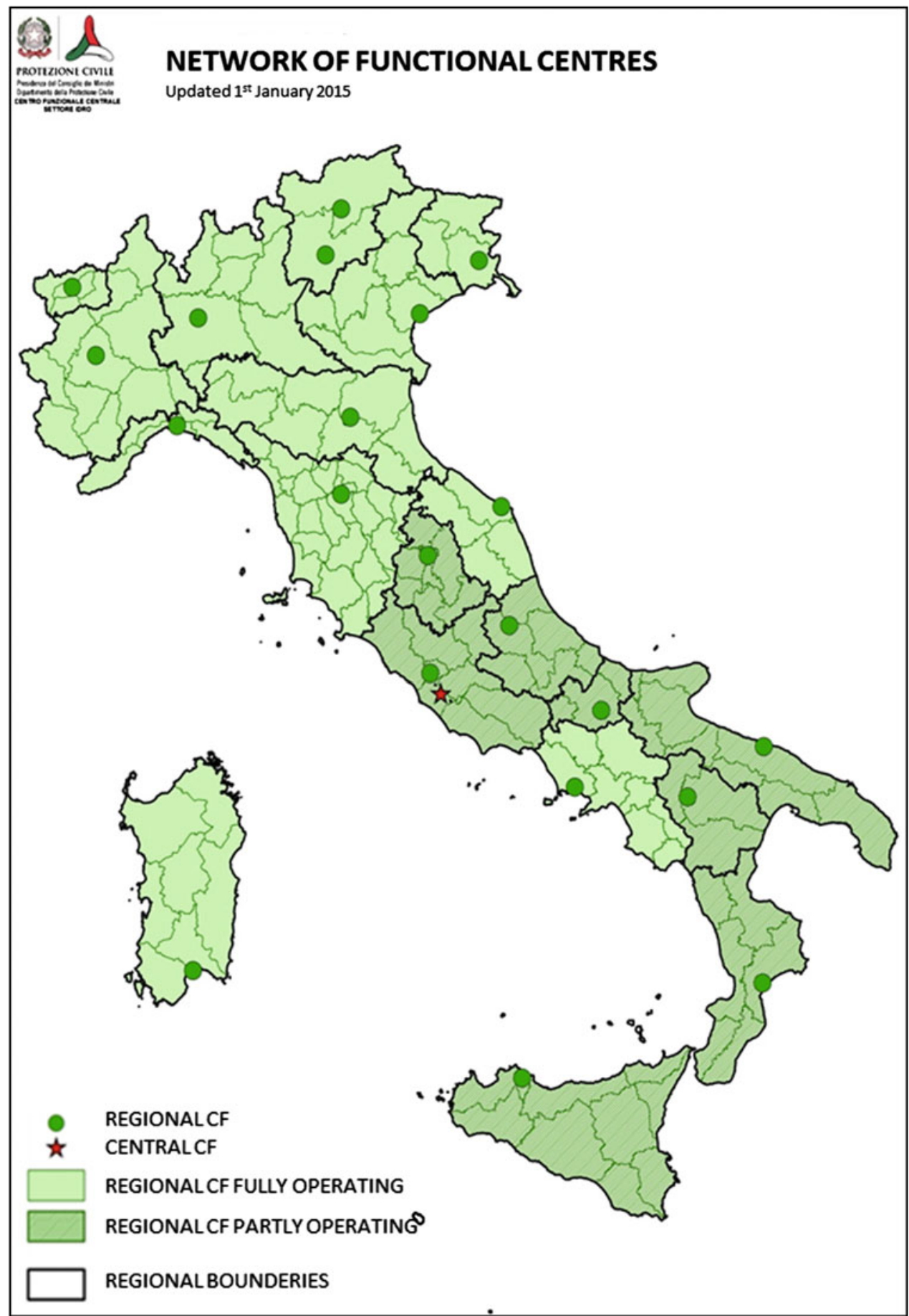

\section{Understanding and Reducing Landslide Disaster Risk}

The widespread distribution of landslides, the occurrence of a number of destructive events, and the cost in terms of human lives and economic resources have led the scientific community and the institutions responsible for land management to a change in their analysis and management of risks related to hydrogeological hazards. After becoming conscious that it was no longer sufficient to tackle the problem during emergencies, providing assistance and restoring the damage, it was realised that instead there is a need to put in place a forecasting policy (identifying the areas at greater risk and estimates of the expected effects) and prevention (risk mitigation), so as to reduce as much as possible the damage expected as a result of landslides. This 


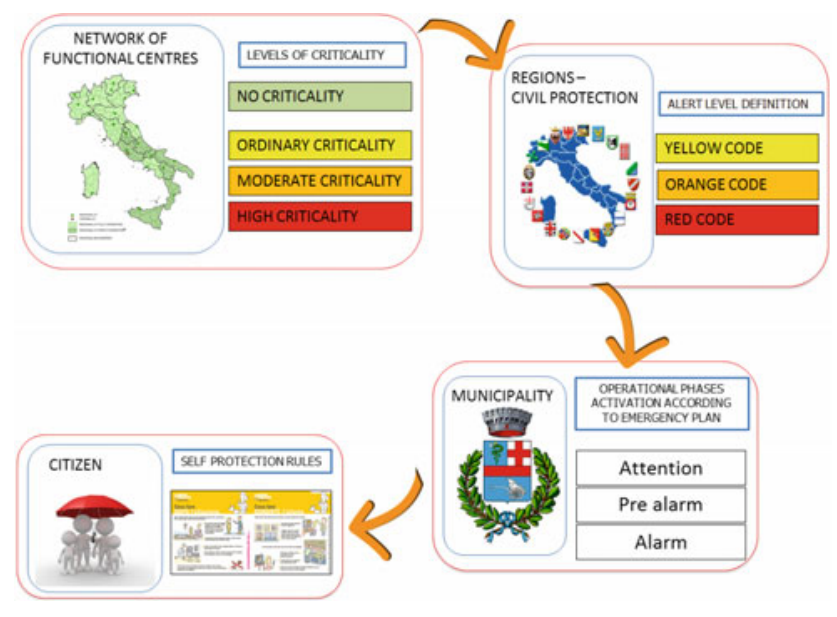

Fig. 2 General diagram of the early warning system for hydraulic and hydrogeological risk

vision is totally coherent with the Sendai Framework position, which shifts the emphasis towards Disaster Risk Management (DRM) as opposed to Disaster Management.

The cost of the damage caused by landslides must take into account the indirect damage associated with loss of productivity, the reduction of real estate asset value, the reduction in tax revenue and other economic impacts, for a more complete and realistic estimate. An understanding of the spatial and temporal evolution of landslides is thus of primary importance for hazard assessment (Guzzetti et al 2005; Van Westen et al. 2006), risk management (Reichenbach et al. 2005), and the definition, design, and implementation of effective prevention and mitigation strategies, which can be effectively reached if long-term monitoring data are made available (Calòa et al. 2014).

\section{The Role of Science and Research}

Within the National Civil Protection Service, the Department of Civil Protection supports research efforts on the assessment of vulnerability and exposure of the population, buildings and critical infrastructure to landslides, and also is involved in national and international research projects (Bianchini et al. 2012; Cigna et al. 2013, 2011; Guzzetti 2000). With regard to deferred-time activities in the pre-event phase, the DPC provides strong support for knowledge application activities concerning landslide risk through a network of Italian Competence Centres (Centres for technological and scientific services) (Bianchini et al. 2012; Cigna et al. 2013, 2011; Guzzetti 2000).

Competence Centres play an important role in supporting the Department in the implementation and development of an Early Warning System (EWS), as well as in daily efforts for its updating and improvement. The role of science in supporting the activities of the Department, in particular concerning the EWS, is to provide support in terms of competences and tools to make the activities that have to be carried out daily more effective. In addition, the opportunity for close cooperation with scientists can address studies to understand the needs of EWS through "ad hoc" applied research (http://drmkc.jrc.ec.europa.eu—March 2016 Newsletter \#2).

The DPC works at a national scale, also providing unified approaches and guidance to be followed at local level for risk mitigation. Therefore, we often support regional and local authorities in integrating science into their policy-making processes. The scientific community, of course, also directly supports the local authorities. In this respect, the role of the universities is very important, as some of them are very active at the local level. Considering the wide variety of scientific findings provided by different researchers on the same subject, it is also very important to favour and support the networking of those universities that conduct research activities and projects in the field of civil protection. In this sense, it is crucial to develop applied research programs and scientific applications that involve the entire scientific community. Moreover, particular attention is dedicated to achieving the objective that the entire national system of civil protection be coordinated, working on the basis of shared and reliable scientific information (http:// drmkc.jrc.ec.europa.eu-March 2016 Newsletter \#2).

But, for other risks, in addition to landslide risk reduction, effort has to be made to share the knowledge, and not only at a National level. In this framework the direct involvement of the DPC in several national but also international research projects is a way to improve and increase understanding of the best practices to be developed, both from a technical point of view and based on procedural approaches, to reduce the impact of landslides on the territory and on the population.

A common EU European approach also allows everyone to benefit from the achievements and practices of the entire scientific community in DRM. The European Commission started with a new initiative addressed to arrange the Disaster Risk Management Knowledge Centre (DRMKC) at EU level. The DRMKC are scientific institutions that provide tools, information, data, processing, and best practices in risk assessment and management, as well as technical-scientific advice on topics relevant to civil protection. This could be useful to facilitate the sharing of best practices, analyses and methodologies among the Member States and to support them for specific requests. It could also play a significant coordinating role in identifying and promoting the application of the most advanced scientific methods to support the countries to meet the goals foreseen in the European Union and Sendai Framework. (http:// drmkc.jrc.ec.europa.eu/ March 2016-Newsletter \#2). 
From a regulation point of view, to support the transition from traditional flood defence strategies to a flood risk management approach at the basin scale in Europe, the EU has adopted the Flood Directive (2007/60/EC) at the end of 2007. One of the major tasks which Member States must carry out in order to comply with this Directive is to map flood hazards and risks in their territory, which will form the basis of future flood risk management plans (de Moel et al. 2009). This Directive represents a strength and a good starting point to share efforts to improve the management of Flood Risk and its reduction. The topic of landslides is included in the Thematic Strategy for Soil Protection (EC 2006a), adopted by the European Commission on 22 September 2006, and also in the legislative package is foreseen the development of a Soil Framework Directive which could include the identification of the risk areas and the development of risk management strategies (Van Den Eeckhaut and Hervás 2012). Like the Flood Directive, a Directive for the landslides could be useful in developing a common approach to risk reduction and improving the knowledge and expertise among different countries.

\section{The Sendai Partnerships 2015-2025 for Global Promotion of Understanding and Reducing Landslide Disaster Risk}

The Sendai Partnerships 2015-2025 for Global Promotion of Understanding and Reducing Landslide Disaster Risk represents the way to improve and share the efforts "to pursue prevention, to provide practical solutions, education, communication, and public awareness raising to reduce landslide disaster risk" (Sassa 2015).

The objective is to reach an ideal Disaster Risk Management decision-making process in which the scientific community is a key actor who contributes by providing a quantitative evaluation of the risk and a cost-benefit evaluation of the possible risk-mitigating actions, supporting the definition of strategies and policies and the implementation of the consequent measures in a timely, effective and efficient way. Their contribution is also relevant in the framework of risk communication and dissemination of a civil protection culture.

The partnership is relevant to facilitating the sharing of best practices, analyses and methodologies to meet the goals foreseen in the Sendai Framework, as well as making better use of existing knowledge at all stages of the DRM cycle, from prevention, reduction and preparedness to response and recovery, at all levels - local, national, European and global - and is therefore a priority both in policy-making and operations.

The direct involvement of Civil Protection Authorities in the Sendai Partnerships 2015-2025 for Global Promotion of
Understanding and Reducing Landslide Disaster Risk is a strong opportunity for strengthening the use of science and technology in policymaking and is also relevant to address efforts to proceed in the direction of compliance with the perspective of DRR and to develop services, procedures and innovations that can be easily integrated in the operational workflow.

For the Civil Protection authorities, the protection of communities and cities is not only a duty, it is also an opportunity for reducing the social and economic losses related to disasters, and to progress towards building more resilient and equal societies.

This perspective is strictly connected with the pillars of the Sendai Framework, as well as with the Seven Global Targets. The following objectives have to be reached as a starting point to improve and increase resilience:

- close collaboration with technical and scientific communities to promote the development of effective monitoring tools and facilitate the use and transfer of new technologies to improve the knowledge of territories and risks;

- the promotion of awareness of risks among the population, developing an effective information system;

- the improvement of training of experts and decision makers;

- identify and promote, in the framework of the Platform, for Disaster Risk Reduction, global and national, a strategic fruitful cooperation

The achievements of the goals require an effort at national and international levels to improve the collaboration and, in this direction, the Sendai Partnerships 2015-2025 for Global Promotion of Understanding and Reducing Landslide Disaster Risk is a key initiative.

Acknowledgements The authors acknowledge the International Consortium on Landslides for its efforts in supporting the authorities in disaster risk reduction; the scientific and research communities that work and support the activities of civil protection with a special effort addressed to cope the user needs and operative requirements, and all the institutions, organizations and the actors involved who spend resources and effort to promote and improve the actions towards a strategy addressed to disaster risk reduction.

\section{References}

Boni G, Pulvirenti L, Silvestro F, Squicciarino G, Pagliara P, Onori R, Proietti C, Candela L, Pisani A R, Zoffoli S (2015) Flood mapping by Italian civil protection. Satellite earth observations in support of disaster risk reduction - special 2015 WCDRR edition

Bianchini S, Cigna F, Righini G, Proietti C, Casagli N (2012) Landslide hotspot mapping by means of persistent scatterer Interferometry. Environ Earth Sciences 
Calò F, Ardizzone F, Castaldo R, Lollino P, Tizzani P, Guzzetti F, Lanari R, Angeli M-G, Pontoni F, Manunta M (2014) Enhanced landslide investigations through advanced DInSAR techniques: the Ivancich case study, Assisi, Italy. Remote Sens Environ 142:69-82

Cigna F, Del Ventisette C, Liguori V, Casagli N (2011) Advanced radar-interpretation of InSAR time series for mapping and characterization of geological processes. Nat Hazards Earth Syst Sci 11:865-881

Cigna F, Bianchini S, Casagli N (2013) How to assess landslide activity and intensity with Persistent Scatterer Interferometry (PSI): the PSI-based matrix approach. Landslides 10:267-283

de Moel H, van Alphen J, Aerts JCJH (2009) Flood maps in Europemethods, availability and use. Nat Hazards Earth Syst Sci 9:289-301

Guzzetti F, Reichenbach P, Cardinali M, Galli M, Ardizzone F (2005) Probabilistic landslide hazard assessment at the basin scale. Geomorphology 72(1-4):272-299
Guzzetti F (2000) Landslide fatalities and evaluation of landslide risk in Italy. Eng Geol 58:89-107

http://www.protezionecivile.gov.it/

http://iononrischio.protezionecivile.it

http://drmkc.jrc.ec.europa.eu/ March 2016-Newsletter \#2

Sassa K (2015) ISDR-ICL Sendai Partnerships 2015-2025 for global promotion of understanding and reducing landslide disaster risk. Landslides 12:631-640

Van Den Eeckhaut M, Hervás J (2012) Landslide inventories in Europe and policy recommendations for their interoperability and harmonization A JRC contribution to the EU-FP7 SafeLand project

Van Westen CJ, Van Asch TWJ, Soeters R (2006) Landslide hazard and risk zonation-why is it still so difficult? Bull Eng Geol Environ 65:167-184
Open Access This chapter is licensed under the terms of the Creative Commons Attribution 4.0 International License (http:// creativecommons.org/licenses/by/4.0/), which permits use, sharing, adaptation, distribution and reproduction in any medium or format, as long as you give appropriate credit to the original author(s) and the source, provide a link to the Creative Commons license and indicate if changes were made.
The images or other third party material in this chapter are included in the chapter's Creative Commons license, unless indicated otherwise in a credit line to the material. If material is not included in the chapter's Creative Commons license and your intended use is not permitted by statutory regulation or exceeds the permitted use, you will need to obtain permission directly from the copyright holder. 